\title{
Rayleigh lidar observations of temperature over Tsukuba: winter thermal structure and comparison studies
}

\author{
S. P. Namboothiri ${ }^{1 *}$, N. Sugimoto ${ }^{1}$, H. Nakane ${ }^{1}$, I. Matsui ${ }^{1}$, and Y. Murayama ${ }^{2}$ \\ ${ }^{1}$ National Institute for Environmental Studies, Tsukuba, Ibaraki 305-0053, Japan \\ ${ }^{2}$ Communications Research Laboratory, Koganei, Tokyo 184-8795, Japan
}

(Received July 27, 1998; Revised June 24, 1999; Accepted June 24, 1999)

\begin{abstract}
Routine lidar observations are in progress at the National Institute for Environmental Studies (NIES), Tsukuba, Japan $\left(36^{\circ} \mathrm{N}, 140^{\circ} \mathrm{E}\right)$, providing vertical profiles of ozone and temperature in the stratosphere and lower mesosphere. The present study focuses the winter thermal structure over Tsukuba and validation/comparison of the lidar derived temperature profiles. Atmospheric temperatures for the altitude region 30-75 km are determined from the neutral density profiles. 33 temperature observations recorded during the winter months of 1995 and 1996 are used in the study. Winter thermal structure is characterized with its variability with an observed stratopause temperature of about $260 \mathrm{~K}$. Although evidence of minor stratospheric warming is seen on some days, there appears to be no direct linkage with major mid winter warmings at the poles. Temperature profiles show evidence of mesospheric temperature inversion layers. For the purpose of validation/comparison of the lidar temperature profiles, other datasets based on rocketsondes, National Meteorological Center (NMC) analyses, Solar Mesosphere Explorer (SME) spacecraft measurements, and CIRA 86 have been used. Encouraging agreements between the lidar and rocket profiles are evident, which confirms the potential of lidar technique for deriving the absolute temperatures in the atmosphere. Climatological comparisons also reveal satisfactory agreement between the lidar and other datasets.
\end{abstract}

\section{Introduction}

The lidar technique has been used for atmospheric probing for several years and proven to be a very powerful technique for investigating the middle atmosphere. By making use of a variety of scattering and absorption processes it is possible to obtain a great deal of information about the atmosphere, its constituents and their changes in both time and space (e.g., Chanin and Hauchecorne, 1981; Hauchecorne and Chanin, 1983; Shibata et al., 1986; Jenkins et al., 1987; Adriani et al., 1991; Carswell et al., 1991). In addition to the important DIAL (Differential Absorption Lidar) measurements of ozone and other trace gas concentration in the atmosphere, lidar measurements of neutral density and temperature in the altitude range $30-65 \mathrm{~km}$ have provided immense information of this region. This region, which is known as the gap region, is generally inaccessible even with high powered Mesosphere-Stratosphere-Troposphere (MST) radars. As a result balloon-borne instruments, rocket sounding, and satellite observations have been the main sources of information of this region. However, these datasets show many discrepancies and contain deficiencies due to poor vertical resolution and their sporadic nature. In this respect, the use of lidar complements the other techniques since the unique feature of lidar is its capability to make measurements of a number of

*Now at Communications Research Laboratory, Koganei, Tokyo 1848795, Japan.

Copy right $(\mathrm{C}$ The Society of Geomagnetism and Earth, Planetary and Space Sciences (SGEPSS); The Seismological Society of Japan; The Volcanological Society of Japan; The Geodetic Society of Japan; The Japanese Society for Planetary Sciences. the important atmospheric parameters with excellent space and time resolution.

Lidar measurements of temperature/density are useful in many ways. Temperature monitoring is important, as temperature controls the rates of chemical reaction and thus the ozone abundance. In general, the dynamical state of the middle atmosphere can be predicted by continually monitoring the temperature, as temperature is the combined manifestation of the dynamical, radiative, and chemical processes occurring in the middle atmosphere (Singh et al., 1996). To this end the formation of the international Network for Detection of Stratospheric Change (NDSC) (Kurylo and Solomon, 1990) was worthwhile. It took initiatives for coordinated monitoring of ozone and temperature in the middle atmosphere. Density and temperature measurements in the middle atmosphere have been used to study a wide range of geophysical phenomena such as tides, planetary and gravity waves, sudden warmings and chemical equilibria (e.g., Chanin and Hauchecorne, 1981; Hauchecorne and Chanin, 1982; Gardner et al., 1989; Whiteway and Carswell, 1994; Namboothiri et al., 1996). Lidar temperature profiles have already been used extensively to validate temperature profiles obtained by the various temperature measuring instruments such as Microwave Limb Sounder (MLS), Cryogenic Limb Array Etalon Spectrometer (CLAES) and Halogen Occultation Experiment (HALOE) aboard UARS (Fishbein et al., 1996; Gill et al., 1996; Hervig et al., 1996). Long-term temperature observations are particularly helpful in the detection of climate changes of terrestrial (greenhouse effects) or extraterrestrial (solar activity) origin (Chanin et al., 1987). 
Also mean temperature variations, induced by changes in the stratospheric ozone, could be detected by such series of measurements.

The ozone lidar at the National Institute for Environmental Studies (NIES) at Tsukuba, Japan $\left(36^{\circ} \mathrm{N}, 140^{\circ} \mathrm{E}\right)$ is continuing observations of ozone concentration, aerosol, and neutral air density on a routine basis. Neutral density measurements are further used to calculate the temperature in the $30-75 \mathrm{~km}$ height region. In this paper we investigate the winter thermal structure over Tsukuba, by using 33 temperature profiles collected during the winter seasons of 1995 and 1996. Also an effort has been made to validate the temperature profiles with other observations/models. In the following section a technical summary of the ozone lidar system operating at NIES together with the methodology employed in the temperature retrieval from the density profiles are presented. In the subsequent section results on the analysis of temperature profiles and validation/comparison studies are given.

\section{Technical Summary and Methodology}

The NIES ozone lidar system is designed primarily to measure the stratospheric ozone using the DIAL technique. It is also used to measure temperature and density using the Rayleigh lidar return of the reference channel. The system has undergone several modifications and improvements in recent years. It comprises two subsystems, a low altitude system (LA) for observations of the troposphere and a high altitude (HA) system for the stratosphere and mesosphere. The present configuration used for high altitude sounding, employs the $\mathrm{XeCl}$ and $\mathrm{XeF}$ excimer lasers to generate light with wavelengths 308 , and $351 \mathrm{~nm}$, respectively. Further the radiation from the $\mathrm{XeCl}$ laser is put into a Raman shifter to generate $339 \mathrm{~nm}$ laser beam. Hence these 3 signals are used for the DIAL measurements, the $308 \mathrm{~nm}$ signal is absorbed by ozone and the $339 \mathrm{~nm}$ and $351 \mathrm{~nm}$ signals serve as the offline wavelengths which are much less absorbed by ozone. As a result two ozone profiles are produced from the two wavelength pairs, which are $308 \mathrm{~nm}-339 \mathrm{~nm}$ pair and $308 \mathrm{~nm}-351$ $\mathrm{nm}$ pair. Temperature and air density measurements are carried out using the $351 \mathrm{~nm}$ laser. The backscattered radiation is collected by a $2 \mathrm{~m}$ Cassegrain telescope. The laser beam pulse at each wavelength is detected by photomultiplier tubes (PMT) which are used for high sensitivity and low sensitivity channels to maintain a wide dynamic range of detectable signal. To avoid strong background echoes, which results in a saturation of PMTs and signal induced noise, the HA system is equipped with a mechanical chopper rotating at a frequency $188 \mathrm{~Hz}$, which provides timing signals for other instruments in the lidar system. Despite the use of narrow field of view of the telescope and small optical bandwidth interference filter which results in significant reduction in sky background, Rayleigh measurements can only be carried out in darkness and clear sky conditions are also necessary. The system has been described in more detail previously (Sugimoto et al., 1989; Nakane et al., 1992).

The basic principles and assumption used for temperature retrieval from the density profiles are the same as that used by Chanin and Hauchecorne (1984) and Wilson et al. (1991). Basically, at altitudes above $30 \mathrm{~km}$ Mie-scattering from the aerosol component is reduced to a negligible level and the atmosphere scatters essentially as a molecular gas. A propagating laser beam undergoes Rayleigh scattering in this gaseous medium and the backscattering detected by the lidar receiver is directly proportional to the molecular density. Thus the relative density profiles can be derived directly from the scattered intensity by simply correcting for rangesquared dependence and normalizing the backscatter profile at a reference altitude. The temperature values are derived from the density measurements by assuming that the atmosphere is in hydrostatic equilibrium and obeys the perfect gas equation. It is also necessary to fit the temperature profile with an atmospheric model at the top level of the measurement. We have used the respective latitude and monthly values of Cospar International Reference Atmosphere-1986 (CIRA-86) (Fleming et al., 1990) model for this purpose. This upper level is taken as the point where the relative statistical uncertainty on the density reaches $15 \%$. Absolute uncertainty, due to the use of model temperature at the top of the profile, decreases rapidly with decreasing altitude. The statistical error of the observed density and temperature depends on the number of photons detected in a range gate during the time of signal integration. So the accuracy depends on the time and height resolution, the observation height, the weather conditions, and adjustment of the optical system. Detailed description on possible uncertainties and error sources in temperature calculations can be seen elsewhere (e.g., Jenkins et al., 1987).

The data used in the present study are taken from the observations conducted during the winter seasons of 1995 and 1996. As mentioned previously, we have 33 nights of observation during this period. The range gate and hardware averaging interval are $150 \mathrm{~m}$ and $10 \mathrm{~min}$, respectively. Background subtraction is carried out for each hardware-averaged profile. Furthermore the signal is integrated into $1 \mathrm{~km}$ bins to improve the signal to noise ratio. It is estimated that the error of hourly mean temperature with a height resolution of $150 \mathrm{~m}$ is about 0.3 and $8 \mathrm{~K}$ at 30 and $60 \mathrm{~km}$, respectively. The measurement range is normally limited to above $30 \mathrm{~km}$ by the presence of aerosols and below $75 \mathrm{~km}$ by the rapidly diminishing signal strength.

\section{Results and Discussion}

\subsection{Winter thermal structure over Tsukuba}

Figure 1 presents the nightly mean temperature profiles recorded during the winter seasons of 1995 and 1996. The hardware averaged photon count profiles are summed over the entire period (typically 3-4 hours) for deriving these nightly mean temperature profiles. Vertical smoothing was applied to these profiles using a running mean over 20 points $(3 \mathrm{~km})$. In the figure the successive profiles are shifted by $50 \mathrm{~K}$ and the date of observation is indicated for each plot. Profiles are also given with the uncertainty limits which are represented by the inner and outer curves. The uncertainty becomes very minimal within the first few kilometers from the top level of observation. From the figure it can be seen that the majority of profiles produced temperature values up to $70-75 \mathrm{~km}$. However, measurement range on certain nights is lowered due to weak backscattered signals. Also shown for validation is the National Meteorological Center (NMC) analysis temperature profile interpolated for Tsukuba, which 
will be discussed in a later section.

The temperature profiles show the typical pattern of winter variability. Such patterns are generally the result of energy and momentum transfer from lower altitudes by planetary waves and increased activity of upward propagating gravity waves during winter season (Houghton, 1978). The stratopause near $44-50 \mathrm{~km}$ is clearly evident in the profiles. Generally the observed stratopause temperature is about $260 \mathrm{~K}$ which is typical for this latitude and season. However, we have observed few days in Jan/Feb 1995 with increasingly warm stratopause with more than $275 \mathrm{~K}$ (e.g., 30 th and 31 st of January, 1st, 3rd, and 17th of February). It is interesting to note the occurrence of warm stratopause on consecutive nights starting from January 30th to 3rd February. We have checked the occurrence of any major stratospheric warming during this period, but no major warming implying the reversal of the stratospheric temperature gradient at polar latitudes and reversal of stratospheric winds were recorded during this period of lidar observations. The increase in temperature may be attributed to planetary wave activity or minor warmings at the poles. Above $55 \mathrm{~km}$ the temperature fluctuations show some evidence of wave like behavior. Such variations may be due to gravity and tidal waves (Chanin and Hauchecorne, 1981).

Another feature observed in the profiles is the indications of temperature inversions on some days at heights above 65 $\mathrm{km}$. Mesospheric inversion layers with about $10 \mathrm{~km}$ thickness are generally observed at midlatitudes during summer and winter seasons. Gravity wave breaking within and above this inversion is considered as one of the reasons behind this phenomenon (Hauchecorne et al., 1987). Sodium lidar studies reported the coincidence of the development of inversion layer and propagation of long-period gravity waves (Bills and Gardner, 1993; She et al., 1993). However, a marked difference is noted for high latitudes. Sodium lidar studies and in-situ rocket measurements conducted at Andoya, Norway during winter and summer conditions observed no evidence of this thermal anomaly (e.g., Neuber et al., 1988; von Zahn and Meyer, 1989). Since our present measurements do not extend above $75 \mathrm{~km}$ we could not go into further details and estimate the centroid height or altitude width of the inversion layer. Efforts are under way to collect more data during the summer season and to increase the observation range to upper mesosphere. This would enable us to study the mesospheric temperature inversion in much more detail including its seasonal variation.

\subsection{Validation/comparison studies}

For the purpose of the validation and comparison of the lidar temperature profiles, we have used datasets acquired by other measurement techniques and models. These datasets include rocket measurements, NMC temperature analyses derived from the NOAA satellite measurements, Solar Mesosphere Explorer (SME) spacecraft measurements, and CIRA 86 model values. Before going to the details of the comparison it is appropriate to give a brief outline of those measurements and models used in the study.

The Japan Meteorological Agency (JMA) is conducting routine rocketsonde observations at Ryori $\left(39^{\circ} \mathrm{N}\right)$, in northern Japan. Information on temperature and wind are available for the altitude region from 20 to $55 \mathrm{~km}$, and the tempera- ture data for the altitude range $30-55 \mathrm{~km}$ are used for the validation of the lidar temperature profiles. The height resolution (linearly interpolated) of rocket data is $1 \mathrm{~km}$. It should be mentioned that Tsukuba and Ryori are located few hundred kilometers $(\sim 350 \mathrm{~km})$ apart and hence the use of Ryori data for validation may be little inappropriate. Since no other temperature datasets for Tsukuba or stations in its immediate vicinity are available we have taken the Ryori dataset for our validation studies. In addition, we are not expecting a major difference in the stratosphere/mesosphere thermal structure between these two sites.

Employing the NOAA series of polar orbiting satellites NMC produces global temperature fields at 18 pressure surfaces from 1000 to 0.4 mbar (Gelman et al., 1986). Temperature profiles interpolated for Tsukuba for 5 pressure levels $(0.4,1.0,2.0,5.0$, and 10 mbar) have been utilized in the present comparison. These pressure surfaces are spaced in approximately $7 \mathrm{~km}$ layers from $31 \mathrm{~km}$ to $55 \mathrm{~km}$.

SME global temperatures have been derived for the upper stratosphere and mesosphere from the analysis of limb radiance profiles and the tabulations were published in a paper by Clancy et al. (1994). They are the averages over 4-5 years of observations, with a vertical resolution of about 4 $\mathrm{km}$ at a fixed local time (1400-1500 LT) and in summer time were restricted to latitudes below $55^{\circ}$ by the presence of polar mesospheric clouds. Temperature data are available for the height range 40-92 km. We have used the climatologies for $35^{\circ} \mathrm{N}$ latitude, which is the nearest latitude to Tsukuba $\left(36^{\circ} \mathrm{N}\right)$.

Cospar International Reference Atmosphere (CIRA 86) (Fleming et al., 1990) climatology is a fairly standard representation of the background middle atmosphere for both data analysis of observations lacking contemporaneous temperature measurements and for modeling photochemistry. The monthly average temperature profiles in the $20-80 \mathrm{~km}$ altitude range are a synthesis of nadir IR sounding observations. Representative climatologies for $35^{\circ} \mathrm{N}$ latitude are used for the comparison.

Figure 1 is also given with the NMC daily temperature analyses for Tsukuba, that correspond to the lidar observation dates. Considering the height resolution $(150 \mathrm{~m})$ of the lidar profiles, it should be noted that the height resolution of the NMC analyses is approximately $7 \mathrm{~km}$ and that makes the comparison less exact. Comparison suggests that except for some disagreements between the top level NMC values and lidar temperature values for certain days, generally both measurements represent almost identical level of temperature field.

The databases of lidar and rocket observations have been examined and we were fortunate to have 5 dates for which both the observations were conducted. Although these measurements were conducted on the same date, there is a time difference between the observations: rocket launchings were carried out during daytime at around 1100 LT and the lidar observations were conducted between 1700 LT and 2200 LT.

Figure 2 shows the temperature profiles obtained by lidar and rocket soundings on the same dates. From the figure it is clear that there are encouraging agreements between the two observations. Except for the large difference noted around $40 \mathrm{~km}$ and near $50 \mathrm{~km}$ in the case of 14 December 1995 , 

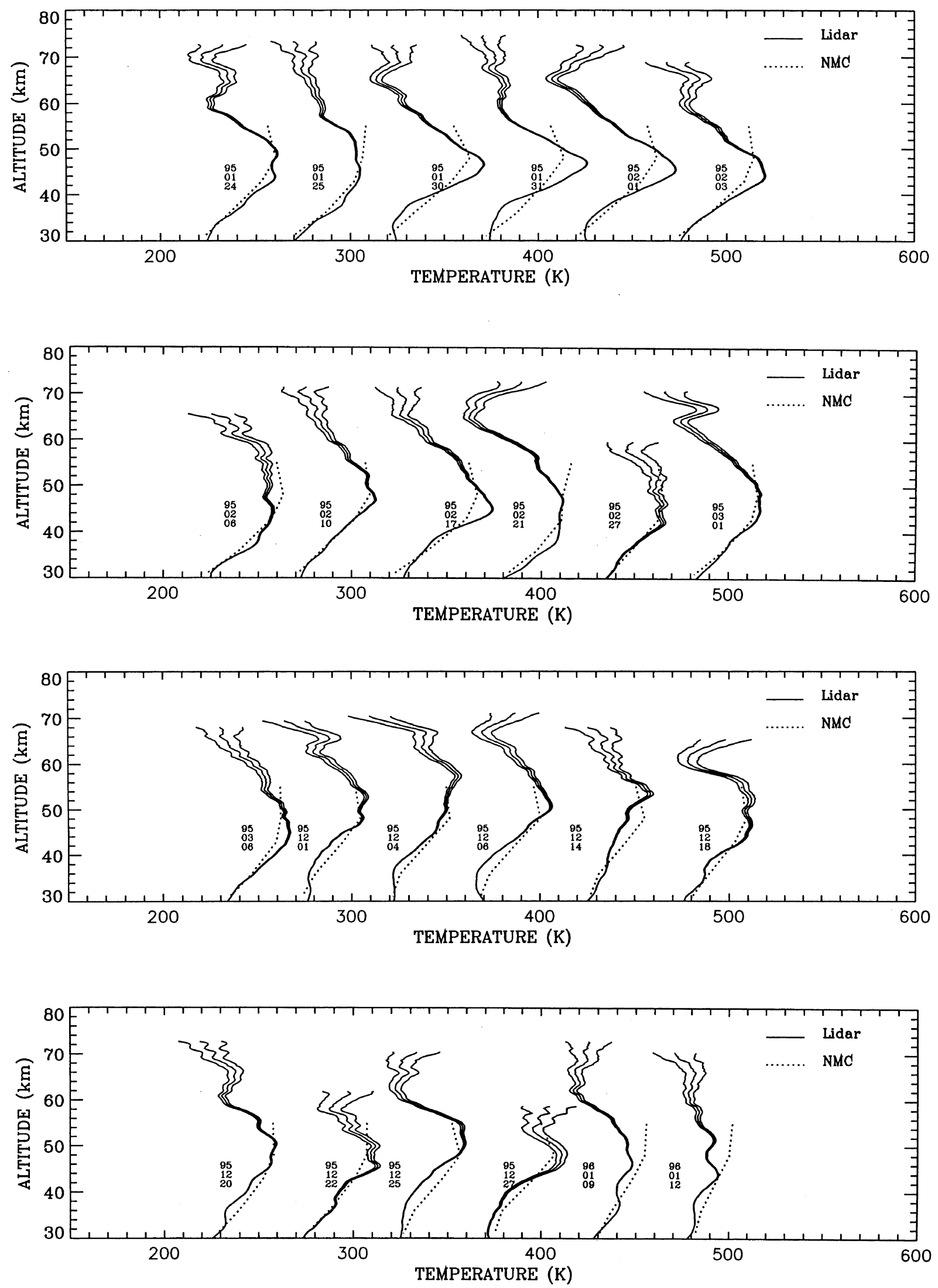

Fig. 1. Nightly mean temperature profiles (solid lines) obtained by NIES ozone lidar during the months January, February of 1995 and 1996 , and March, December of 1995. The observational date is indicated for each plot. Inner and outer lines represent the measurement uncertainty. Labels on the temperature scale refer only to the first profile, while subsequent profiles are shifted by $50 \mathrm{~K}$. Dotted lines indicate the corresponding NMC daily temperature analyses for Tsukuba. 

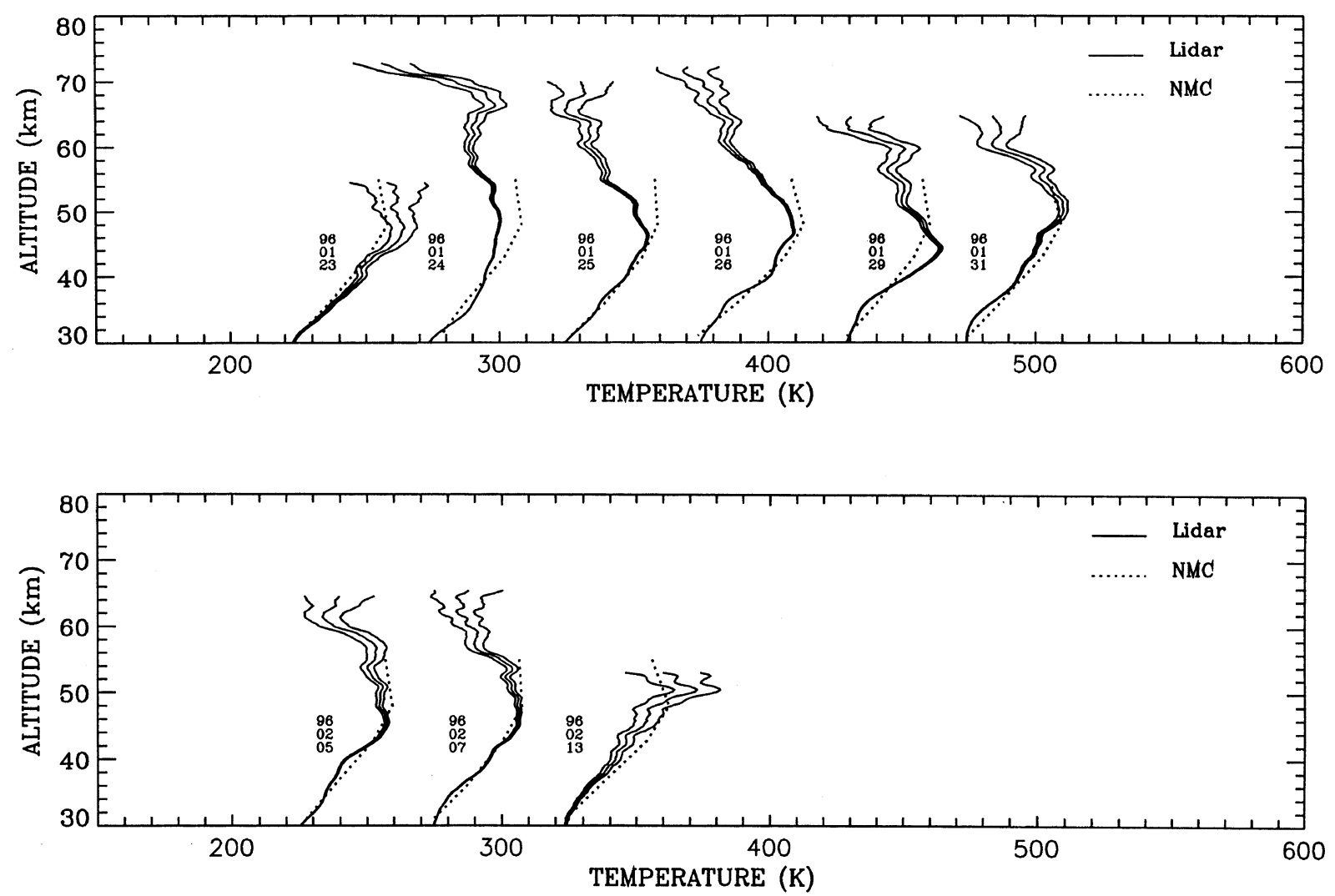

Fig. 1. (continued).

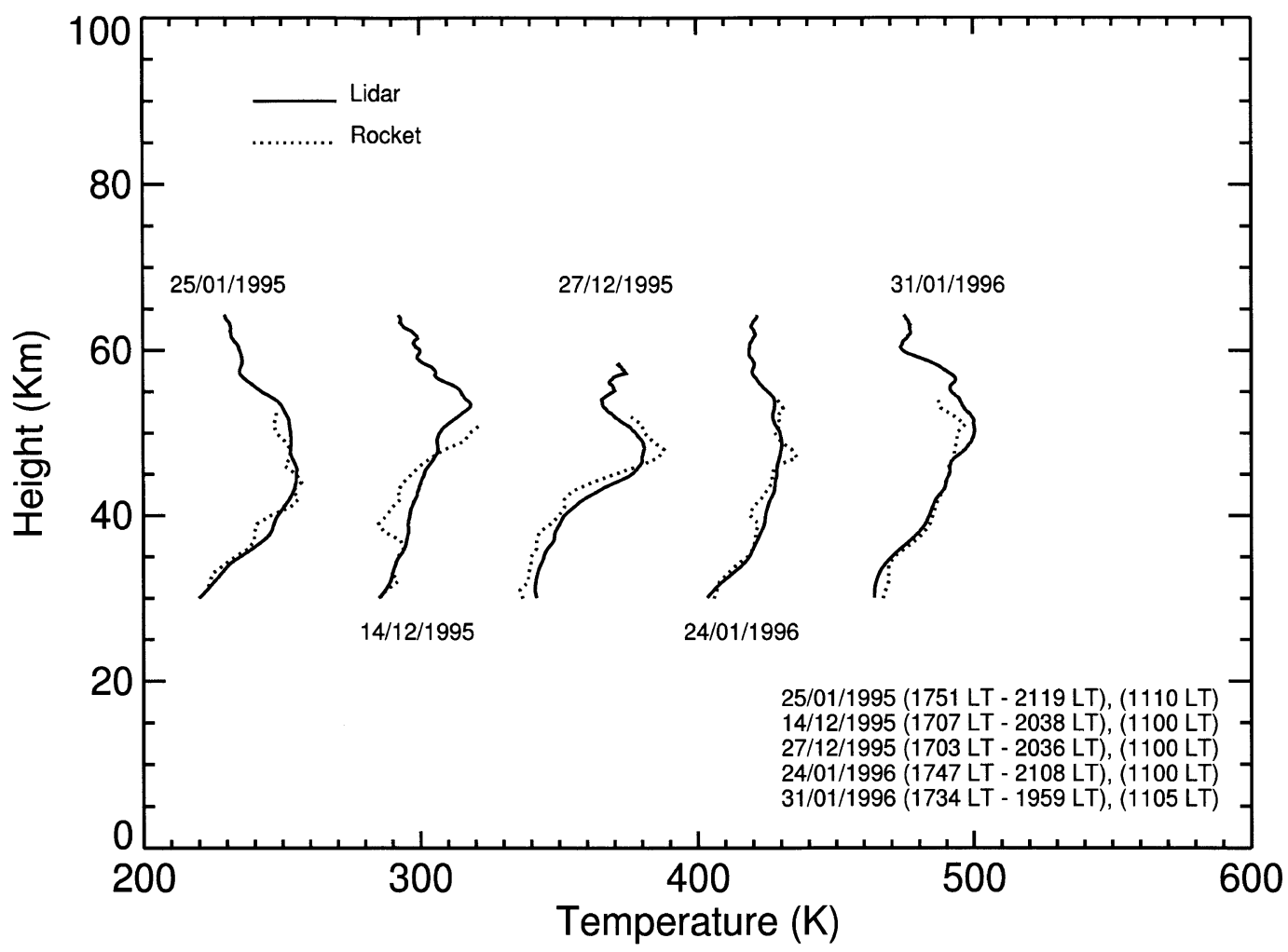

Fig. 2. Rocket and lidar temperature profiles for 5 individual days. Solid and dotted lines represent the lidar and rocket profiles, respectively. Labels on the temperature scale refer only to the first profile, while subsequent profiles are shifted by $60 \mathrm{~K}$. Time interval of the lidar profile and the time of rocket profile for the observation dates are also shown. 

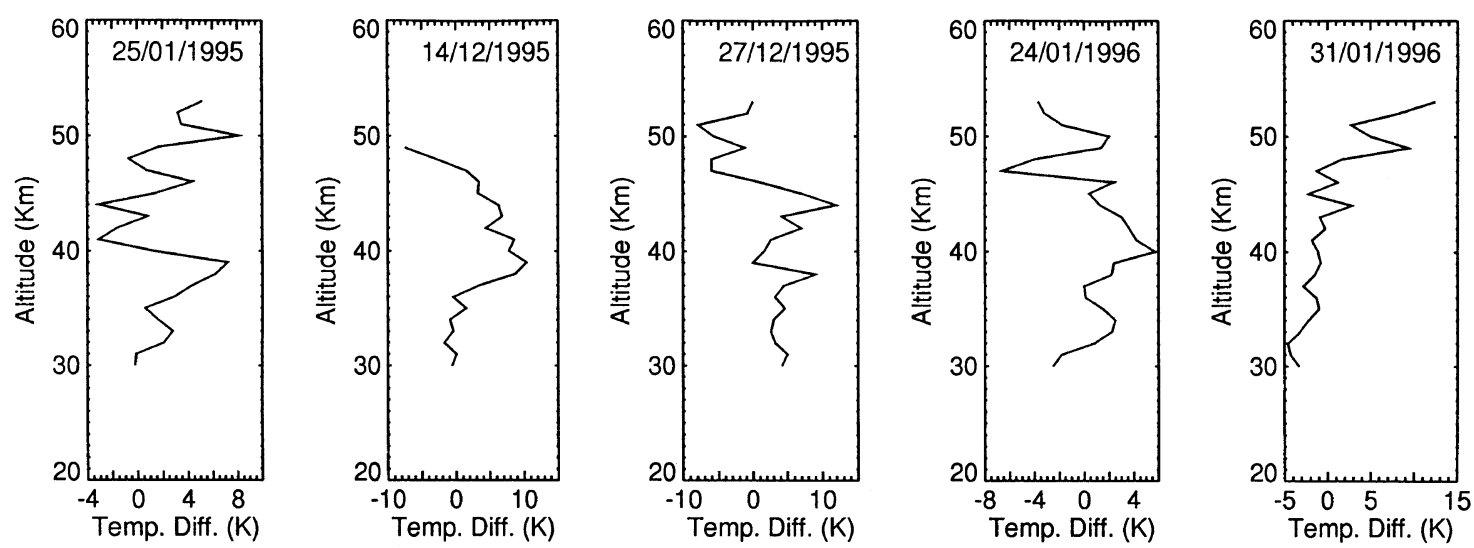

Fig. 3. Temperature difference between the NIES lidar measurements at Tsukuba and rocket measurements at Ryori. Positive differences are for lidar temperatures warmer than the rocket temperatures.

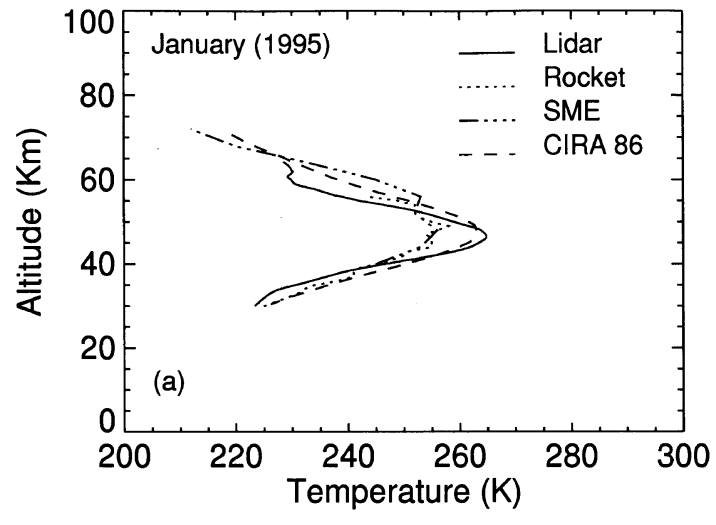

(a)

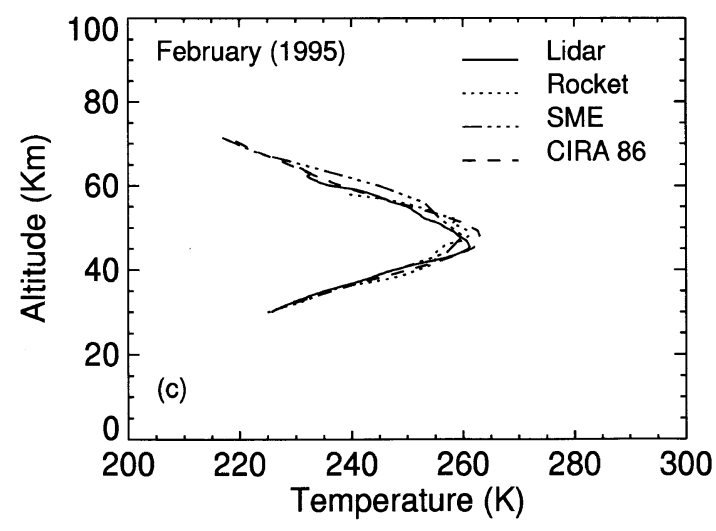

(c)

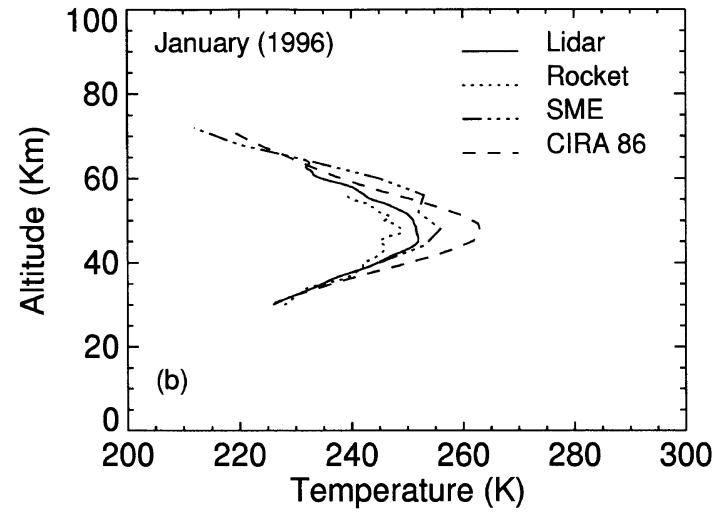

(b)

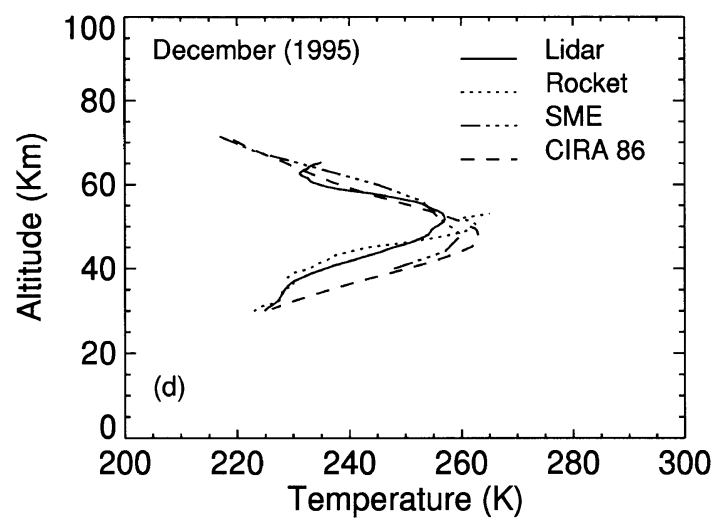

(d)

Fig. 4. Monthly mean temperature profiles for January, February, and December. Various datasets such as lidar, rocket, SME, and CIRA 86 are presented.

all the profiles show very good resemblance. This larger differences noted for 14 December 1995 may be due to some local disturbances. The stratopause is situated at the same altitude in both the observations. The overall scenario is promising considering the difference in measurement times or the separation of the measurement sites. Also it should be indicated that the lidar temperatures represent a $2-4$ hour average while the rocket profile is an instantaneous "snapshot". This could be the cause of the discrepancy as any fast wave present in the rocket data would be smoothed by the lidar.

The differences between the rocket temperature and the 
lidar temperature are shown in Fig. 3. Positive temperature differences correspond to warmer lidar temperatures. The differences noted between the two measurements are in the range of $0-5 \mathrm{~K}$ in the majority of cases. Also there are some evidences of 5-10 $\mathrm{K}$ differences between the two independent measurements. As stated previously, the differences noted may be related to the time difference of observation and the distance between the two sites or the different integration. It seems lidar temperatures are generally warmer than those measured by rocketsondes.

Figure 4 presents a composite picture of a detailed comparison of mean temperature profiles. Climatologies for January, February and December are shown. Lidar, rocket, SME, and CIRA 86 databases are presented in the figure. In Figs. 4(a) and (b) lidar temperature profiles for January 1995 and 1996 and the corresponding monthly means for rocket observation are separately given. For February and December (Figs. 4(c) and (d)) lidar and rocket profiles are representative of the year 1995. SME and CIRA 86 profiles in the plots represent the respective months.

Climatological trends observed in the plots are very interesting. In the case of January there is a good agreement between different observations and models at the altitude $30-40 \mathrm{~km}$. Above this altitude deviation between individual measurements become pronounced. However, taking the lidar plots as reference, we can see that the maximum deviation with other datasets is not more than $15 \mathrm{~K}$. The lidar profile for 1995 corresponds well with the CIRA 86 model, but in the case of 1996 it is more aligned to the rocket values. SME temperatures seem to be rather high compared to other values. A better agreement is evident in the case of February (Fig. 4(c)). For all the plots temperature values show good resemblance in the entire altitude region. Stratopause is located at around $48 \mathrm{~km}$ in each plots and its temperature is about $260 \mathrm{~K}$. The December case in Fig. 4(d) also predicts good agreement between the lidar and rocket profiles. CIRA 86 model temperatures seem to be higher in the $30-45 \mathrm{~km}$ region and above that better agreement is evident between the compared profiles.

Here we have compared the lidar temperature with a variety of other measurements and models. The results of our study show only a qualitative agreement between the lidar measurement and other measurements or models. It should be remembered that the measurements used in the study are not obtained simultaneously and strictly over the same site, the discrepancies could be interpreted as spatial and temporal geophysical effects. The method of temperature retrieval is different for each technique and to a certain extent this can contribute to the observed difference. Intercomparison of coincident temperature measurements using two lidars also reported little difference in temperature values (Singh et al., 1996).

\section{Concluding Remarks}

In the present study we have focused on the winter thermal structure over Tsukuba and validation/comparison results of the temperature profiles derived by using the ozone lidar system at the National Institute for Environmental Studies, Tsukuba. The lidar is capable of measuring the temperature field in the altitude region $30-75 \mathrm{~km}$. The available tempera- ture profiles of the winter seasons of 1995 and 1996 are used in this study. Validation and comparison of the temperature profiles are carried out using other datasets such as rocket, NMC, SME, and CIRA 86. Lidar and rocket observations of the same dates show encouraging agreements between the profiles. Comparison of the lidar profiles and NMC daily temperature analyses for the corresponding dates also shows relatively good agreements. Climatological comparison of the lidar temperature with other databases shows certain levels of consistency in their trends.

The temperature profiles are being used to study wave activity in the middle atmosphere. Aiming a detailed study on temperature climatology and gravity waves, data collection is being extended to other seasons as is the duration of nightly observations. The lidar is now equipped with a Raman channel, which permits observations of the temperature fields in the lower stratosphere.

Acknowledgments. One of the authors (S.P.N.) is grateful to the Japan Environment Agency for providing the financial assistance to work at NIES as an EF Fellow. The authors would like to express their sincere thanks to the Japan Meteorological Agency (JMA) for providing the Ryori rocketsonde data. The NMC temperature measurements were provided by Roger Lin at NOAA/NCEP.

\section{References}

Adriani, A., G. P. Gobbi, F. Congeduti, and G. Di Donfrancesco, Lidar observations of stratospheric and mesospheric temperature: November 1988-November 1989, Ann. Geophysicae, 9, 252-258, 1991.

Bills, R. E. and C. S. Gardner, Lidar observations of the mesosphere region temperature structure at Urbana, J. Geophys. Res., 98, 1011-1021, 1993.

Carswell, A. I., S. R. Pal, W. Steinbrecht, J. A. Whiteway, A. Ulitsky, and T. Y. Wang, Lidar measurements of the middle atmosphere, Can. J. Phys., 69, 1076-1086, 1991.

Chanin, M. L. and A. Hauchecorne, Lidar observation of gravity and tidal waves in the stratosphere and mesosphere, J. Geophys. Res., 86, 97159721, 1981 .

Chanin, M. L. and A. Hauchecorne, Lidar studies of temperature and density using Rayleigh scattering, MAP Handbook, 13, 87-98, 1984.

Chanin, M. L., N. Smires, and A. Hauchecorne, Long term variation of the temperature of the middle atmosphere at mid-latitude: dynamical and radiative causes, J. Geophys. Res., 92, 10,933-10,941, 1987.

Clancy, R. T., D. W. Rusch, and M. T. Callan, Temperature minima in the average thermal structure of the middle mesosphere $(70-80 \mathrm{~km})$ from analysis of 40- to 92-km SME global temperature profiles, J. Geophys. Res., 99, 19,001-19,020, 1994.

Fishbein, E. F., R. E. Cofield, L. Froidevaux, R. F. Jarnot, T. Lungu, W G. Read, Z. Shippony, J. W. Waters, I. S. McDermid, T. J. McGee, U. Singh, M. Gross, A. Hauchecorne, P. Keckhut, M. E. Gelman, and R. M. Nagatani, Validation of UARS Microwave Limb Sounder temperature and pressure measurements, J. Geophys. Res., 101, 9983-10,016, 1996.

Fleming, E. L., S. Chandra, J. J. Barnett, and M. Corney, Zonal mean temperature, pressure, zonal wind and geopotential height as functions of latitude, Adv. Space Res., 10, 1211-1259, 1990.

Gardner, C. S., M. S. Miller, and C. H. Liu, Rayleigh lidar observations of gravity wave activity in the upper stratosphere at Urbana, Illinois, $J$. Atmos. Sci., 46, 1838-1854, 1989.

Gelman, M. E., A. J. Miller, K. W. Johnson, and R. M. Nagatani, Detection of long-term trends in global stratospheric temperature from NMC analyses derived from NOAA satellite data, Adv. Space Res., 6, 17-26, 1986.

Gill, J. C., P. L. Bailey, S. T. Massie, L. V. Lyjak, D. P. Edwards, A. E. Roche, J. B. Kumer, J. L. Mergenthaler, M. R. Gross, A. Hauchecorne, P. Keckhut, T. J. McGee, I. S. McDermid, A. J. Miller, and U. Singh, Accuracy and precision of cryogenic limb array etalon spectrometer (CLAES) temperature retrievals, J. Geophys. Res., 101, 9583-9602, 1996.

Hauchecorne, A. and M. L. Chanin, A mid-latitude ground based lidar study of stratospheric warmings and planetary waves propagation, J. Atmos Terr. Phys., 44, 577-583, 1982.

Hauchecorne, A. and M. L. Chanin, Mid-latitude observations of planetary waves in the middle atmosphere during the winter of 1981-1982, J. 
Geophys. Res., 88, 3843-3849, 1983.

Hauchecorne, A., M. L. Chanin, and R. Wilson, Mesospheric temperature inversion and gravity wave breaking, Geophys. Res. Lett., 14, 935-936, 1987.

Hervig, M. E., J. M. Russell, III, L. L. Gordley, S. R. Drayson, K. Stone, R. E. Thompson, M. E. Gelman, I. S. McDermid, A. Hauchecorne, P. Keckhut, T. J. McGee, U. N. Singh, and M. R. Gross, A validation of temperature measurements from the Halogen Occultation Experiment, $J$. Geophys. Res., 101, 10,277-10,286, 1996.

Houghton, J. T., The stratosphere and mesosphere, Q. J. R. Meteorol. Soc., 104, 1-29, 1978.

Jenkins, D. B., D. P. Wareing, L. Thomas, and G. Vaughan, Upper stratospheric and mesospheric temperature derived from lidar observations at Aberystwyth, J. Atmos. Terr. Phys., 49, 287-298, 1987.

Kurylo, M. J. and S. Solomon, Network for the detection of stratospheric change, NASA Rep., Code EEU, 1990.

Nakane, H., S. Hayashida, Y. Sasano, N. Sugimoto, I. Matsui, and A. Minato, Vertical profiles of temperature and ozone observed during DYANA campaign with the NIES ozone lidar system at Tsukuba, $J$. Geomag. Geoelectr., 44, 1071-1083, 1992.

Namboothiri, S. P., T. Tsuda, M. Tsutsumi, T. Nakamura, C. Nagasawa, and M. Abo, Simultaneous observations of mesospheric gravity waves with the MU radar and a sodium lidar, J. Geophys. Res., 101, 4057-4063, 1996.

Neuber, R., P. von der Gathen, and U. von Zahn, Altitude and temperature of the mesopause at $69^{\circ} \mathrm{N}$ latitude in winter, J. Geophys. Res., 93, 11093-
$11101,1988$.

She, C. Y., J. R. Yu, and H. Chen, Observed thermal structure of a midlatitude mesopause, Geophys. Res. Lett., 20, 567-570, 1993.

Shibata, T., T. Fukuda, and M. Maeda, Density fluctuations in the middle atmosphere over Fukuoka observed by an XeF Rayleigh lidar, Geophys. Res. Lett., 13, 1121-1124, 1986.

Singh, U. N., P. Keckhut, T. J. McGee, M. R. Gross, A. Hauchecorne, E. F. Fishbein, J. W. Waters, J. C. Gille, A. E. Roche, and J. M. Russell, III, Stratospheric temperature measurements by two collocated NDSC lidars during UARS validation campaign, J. Geophys. Res., 101, 10,28710,297. 1996

Sugimoto, N., Y. Sasano, H. Nakane, S. Hayashida-Amano, I. Matsui, and A. Minato, Multiple wavelength laser radar for measuring the stratospheric and tropospheric ozone profiles, Oyobutsuri, 56, 1385-1397, 1989.

von Zahn, U. and W. Meyer, Mesopause temperatures in polar summer, $J$. Geophys. Res., 94, 14,647-14,651, 1989.

Whiteway, J. A. and A. I. Carswell, Rayleigh lidar observations of thermal structure and gravity wave activity in the high arctic during a stratospheric warming, J. Atmos. Sci., 51, 3122-3136, 1994.

Wilson, R., M. L. Chanin, and A. Hauchecorne, Gravity waves in the middle atmosphere observed by Rayleigh lidar 1. Case studies, J. Geophys. Res., 96, 5153-5167, 1991.

S. P. Namboothiri (e-mail: nambooth@crl.go.jp), N. Sugimoto, H. Nakane, I. Matsui, and Y. Murayama 